\title{
Recent advances in understanding cholangiocarcinoma
}

\author{
Pedro Luiz Serrano Uson Junior ${ }^{1,5}$ Mansi Arora ${ }^{1,2}$ James M. Bogenberger ${ }^{1,2}$ Mitesh J. Borad ${ }^{1,2,3,4 *}$ \\ ${ }^{1}$ Division of Hematology and Medical Oncology, Mayo Clinic, Scottsdale, Arizona, USA \\ ${ }^{2}$ Department of Molecular Medicine, Mayo Clinic, Rochester, Minnesota, USA \\ ${ }^{3}$ Center for Individualized Medicine, Mayo Clinic, Rochester, Minnesota, USA \\ ${ }^{4}$ Mayo Clinic Cancer Center, Mayo Clinic, Phoenix, Arizona, USA \\ ${ }^{5}$ Hospital Israelita Albert Einstein, Sao Paulo, Brazil
}

\begin{abstract}
The definition of cholangiocarcinoma (CCA) encompasses all tumors originating in the epithelium of the bile ducts, including the intrahepatic bile ducts (ICCA) and extrahepatic bile ducts (ECCA). The incidence of ICCA and ECCA has increased in the last few decades, and molecular advances in both entities have brought understanding of their differences and allowed treatment advances aimed at personalized therapy. In this review, we discuss recent progress in the molecular landscape of CCAs, emerging treatment biomarker-guided strategies, and future insights into the management of advanced disease.
\end{abstract}

\section{Keywords}

Cholangiocarcinoma, biliary tract cancer, FGFR2, IDH1, PD-1

\section{Peer Review}

The peer reviewers who approve this article are:

1. Xin Chen, Department of Bioengineering and Therapeutic Sciences and Liver Center, University of California, California, USA

Competing interests: No competing interests were disclosed.

2. Hassan Malik, Department of Hepato-Biliary Surgery, University Hospital Aintree, Liverpool, UK Competing interests: No competing interests were disclosed.

\footnotetext{
*Corresponding author: Mitesh J. Borad (borad.mitesh@mayo.edu)

Competing interests: The authors declare that they have no competing interests.

Grant information: The authors declare that no grants were involved in supporting this work.

Copyright: (C) 2020 Borad MJ et al. This is an open access article distributed under the terms of the Creative Commons Attribution License, which permits unrestricted use, distribution, and reproduction in any medium, provided the original work is properly cited.

How to cite this article: Uson Junior PLS, Arora M, Bogenberger JM and Borad MJ. Recent advances in understanding cholangiocarcinoma.

Faculty Reviews 2020 9:(15) https://doi.org/10.12703/b/9-15
}

Published: 19 Nov 2020, Faculty Reviews 9:(15) https://doi.org/10.12703/b/9-15 


\section{Introduction}

Intrahepatic cholangiocarcinoma (ICCA), extrahepatic cholangiocarcinoma (ECCA), and gallbladder cancer are designated as biliary tract cancers (BTCs). In 2019, in the United States, there was an estimated total of 54,390 new cases (liver cancer and BTC), and there were approximately 35,740 deaths due to these diseases in the same year ${ }^{1,2}$. The definition of an ICCA is a cholangiocarcinoma (CCA) detected inside the hepatic parenchyma, whereas ECCA is a type of tumor located outside the liver parenchyma. These tumors can arise in any portion of the extrahepatic bile duct and can be additionally classified as hilar or distal $\mathrm{CCA}^{1}$. In this review article, we discuss several reports that present the best evidence for the management of CCA and molecular insights of personalized approaches, including checkpoint inhibitors and fibroblast growth factor receptor (FGFR) inhibitors.

\section{Localized cholangiocarcinoma}

The treatment for localized CCA is based on the complete resection of the primary tumor. Analysis of data from 535 patients with ICCA resected in a multi-institutional database revealed a median overall survival (OS) of 27.4 months. Most disease-specific cancer deaths $(65.6 \%)$ occurred in the 24 months after surgery. Factors associated with worse survival include larger tumor size, multifocal disease, vascular invasion, lymph node metastasis, and advanced stage. One of the limitations of this study was the absence of data about the perioperative regimens used $^{3}$. The recommendation for adjuvant chemotherapy in complete resected BTC is based on two randomized controlled trials. In the phase III trial BILCAP, 447 patients with BTCs were randomized after surgical resection to receive capecitabine or observation. In both groups, $38 \%$ of patients had a positive margin resection. Although the study did not reach statistical significance in the intention-to-treat analysis, in the pre-specified per-protocol analysis, the mean OS was 53 months (95\% confidence interval $[\mathrm{CI}] 40$ months to not reached) in the capecitabine group and 36 months (95\% CI 30-44) in the observation group (adjusted hazard ratio [HR] 0.75 , 95\% CI $0.58-0.97$; $P=0.028$ ). These results encourage the use of adjuvant capecitabine as an option for patients with resected $\mathrm{BTC}^{4}$. A multicenter prospective randomized controlled phase III trial evaluated a combination of mitomycin $\mathrm{C}$ and fluorouracil in resected pancreatobiliary carcinomas. An unplanned subgroup analysis in gallbladder carcinoma suggested improvement in 5-year survival rate in the chemotherapy group (26.0\%) compared with the control group $(14.4 \%)(P=0.0367)$. No differences were seen with 5-year survival among patients with $\mathrm{CCA}^{5}$.

Concurrent chemo-radiotherapy is often used in the perioperative strategy for ECCA. A phase II study with 79 resected BTC patients (SWOG S0809) treated with adjuvant chemotherapy (gemcitabine and capecitabine) and capecitabine plus radiotherapy provided data for this modality. With a manageable safety profile, the 2-year survival was $65 \%$, with a median OS of 35 months $^{6}$. For patients with unresectable hilar CCA, multimodal therapy with neoadjuvant chemotherapy and radiotherapy and liver transplant has emerged as a promising option, as described in findings from the Mayo Clinic and other groups ${ }^{7-9}$. A multicenter retrospective study of 216 patients with early stage unresectable peri-hilar CCA who were treated with neoadjuvant concurrent chemotherapy and radiotherapy followed by liver transplantation showed promising results after rigorous selection for the procedure. The overall recurrence-free survival rate in 5 years was $65 \%{ }^{10}$. A retrospective comparison between hilar CCA patients treated with upfront resection with curative intent or neoadjuvant treatment followed by liver transplantation found better OS associated with the latter strategy, with 3-year survival rates of $72 \%$ versus $33 \%$ and 5-year survival rates of $64 \%$ versus $18 \%, P<0.001^{11}$. Important questions regarding liver transplantation should be addressed considering limited supply of liver allografts and the need for life-long immunosuppression $^{12}$. Data for specific recommendations in the perioperative treatment of BTCs are limited because of the results and quality of the available trials; prospective studies should be designed to address resection strategies ${ }^{1,12}$. Gemcitabine plus oxaliplatin is not recommended in the adjuvant setting for resected BTCs based on recent negative randomized phase III trials $^{13,14}$.

\section{Advanced disease}

Chemotherapy is often used for the management of patients with metastatic CCA. The randomized phase III trials ABC-02 and $\mathrm{ABC}-06$ provide results from chemotherapy regimens in the first line and second line of systemic treatment in BTC. In the first trial, $\mathrm{ABC}-02,410$ locally advanced or metastatic patients were randomized to receive cisplatin and gemcitabine or gemcitabine alone. After a median follow-up of 8.2 months, OS was improved with the addition of cisplatin to gemcitabine: median OS was 11.7 months in the cisplatin-gemcitabine group and 8.1 months in the gemcitabine-alone group (HR 0.64, 95\% CI $0.52-0.80 ; P<0.001)$. The median progression-free survival was also improved with the combination: 8.0 months versus

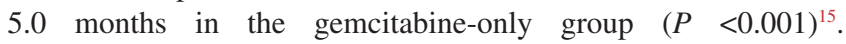
ABC-06 was a randomized phase III trial of the chemotherapy regimen modified fluorouracil plus oxaliplatin (FOLFOX) in the second-line setting for advanced BTC. Patients with disease progression on cisplatin and gemcitabine were randomized to either active symptom control (ASC) or ASC plus modified FOLFOX. From 27 March 2014 to 4 January 2018, 162 patients were randomized, 81 in each arm. Median OS and survival rates were improved with chemotherapy; median OS was 6.2 months with chemotherapy and 5.3 months with ASC alone. The 6-month and 12-month survival rates for chemotherapy plus ASC were $50.6 \%$ and $25.9 \%$, respectively, and for ASC alone were $35.5 \%$ and $11.4 \%$, respectively. Based on these results, modified FOLFOX could be considered a standard chemotherapy regimen for the treatment of patients who failed cisplatin plus gemcitabine in first-line systemic treatment ${ }^{16}$.

Lately, several studies have demonstrated potential targets for personalized treatment in $\mathrm{BTCs}^{17}$. Genomic profiling in large cohorts of patients with BTC aim to assist the stratification of patients to targeted therapy. Overall, the tumor mutational 
burden (TMB) in BTC is low; in an analysis of 803 patients with biliary cancers, the median TMB was $3.0(0.8-6.1) \mathrm{Mut} / \mathrm{Mb}^{18}$. In another cohort with 239 cases, just 6\% were considered high TMB, with the cutoff of $11.13 \mathrm{Mut} / \mathrm{Mb}^{19}$. The genes most frequently associated with genomic alterations are TP53, KRAS, ARID1A, SMAD4, CCND1, MET, MDM2, CDKN2A, and CDKN2B, and the most common actionable gene targets are FGFR2 fusions, IDH1 mutations, and HER-2 and MET amplifications; actionable targets are commonly observed in $\mathrm{ICCA}^{17,18}$. It is estimated that between 13 and $17 \%$ of ICCAs harbor genomic alterations in the FGFR2 gene and that most of these alterations (i.e. fusions) predict tumor sensitivity to anti-FGFR2 tyrosine kinase inhibitors ${ }^{17,18}$. BJG 398 (infigratinib), a pan-FGFR kinase inhibitor, was first evaluated in a phase II study in patients with FGFR genomic alterations, and FGFR2 fusions were detected in $48(78.7 \%)$ patients. In this study, 61 patients were treated. The overall response rate was $14.8 \%$ and disease control rate was $75.4 \%$. In this subgroup of chemotherapy-refractory patients, the responders were restricted to cases with FGFR2 fusions ${ }^{20}$. Another pan-FGFR kinase inhibitor, pemigatinib, was similarly evaluated in a phase II trial. Patients who had disease progression to at least one systemic treatment received oral pemigatinib. The primary endpoint was response rate, and other outcomes were estimated including OS and safety. There were three cohorts of patients in this study: cohort A included patients with FGFR gene rearrangements/fusions. Of 107 patients (cohort A), the overall response rate was $35.5 \%$ (95\% CI 26.5-45.4\%), disease control rate was $82 \%$, and median OS was 21.1 months. The most common treatment-related adverse event was hyperphosphatemia $(60 \%)^{21}$. Infigratinib and pemigatinib are being further evaluated in randomized phase III trials in previously untreated advanced BTC (NCT03773302, NCT03656536). Despite the encouraging results of these molecules, emerging mutations and acquired resistance have been observed in several cases after exposure to both drugs ${ }^{17,22-24}$. TAS 120 is an irreversible FGFR1-4 inhibitor and was the first to be evaluated in a group of 45 BTC patients harboring FGFR aberrations. In this study, 13 patients had previously received a reversible FGFR inhibitor. The overall response rate was $25 \%$, and four patients previously treated with an FGFR inhibitor had a partial clinical response ${ }^{25}$. The efficacy of TAS 120 in acquired FGFR mutations after FGFR reversible inhibitors in ICCA was evaluated and confirmed in cell line models, but limited activity against some acquired mutations after infigratinib exposure including V565F was observed ${ }^{22}$. Interestingly, Debio-1347, another pan-FGFR inhibitor, remained active against this specific mutation ${ }^{22,26}$. Other pan-FGFR kinase inhibitors are being evaluated in ICCA with FGFR fusions, including erdafitinib and derazantinib; both drugs demonstrated anti-tumor activity and a tolerable safety profile in phase I/II trials ${ }^{27,28}$. With all of these drugs targeting FGFR, a new understanding of the relationship between the structure of inhibitory molecules of FGFR and the acquisition of resistant mutations will be necessary for the development of future studies in the management of these patients.
One of the most common driver genetic alterations in ICCA is gain-of-function mutations in the isocitrate dehydrogenase (IDH)-1 enzyme, observed in 20-25\% of ICCA patients ${ }^{29,30}$. Ivosidenib, a targeted inhibitor of mutant IDH1, was initially evaluated in 73 patients with mutant advanced CCA, demonstrating a tolerable safety profile ${ }^{31}$. Furthermore, the drug was compared with placebo in a randomized phase III trial of patients previously treated with chemotherapy and who had disease progression with the treatment. ClarIDHy is a randomized phase III trial in metastatic IDH1 mutant CCA. In this trial, 185 patients were randomized to ivosidenib or placebo in a $2: 1$ fashion. In this group of patients, $46 \%$ had two prior systemic treatments. The primary end-point of progression-free survival was met; the median progression-free survival for ivosidenib was 2.7 months and for placebo was 1.4 months (HR 0.37, 95\% CI 0.25-0.54; $P<0.0001)$. OS with ivosidenib was not statistically significantly different to the placebo arm. However, in this trial, $57 \%$ of placebo patients crossed over to ivosidenib. Ivosidenib is not currently approved by the US Food and Drug Administration (FDA) for the treatment of IDH1 mutant advanced CCA ${ }^{32}$. BAY 1436032 is another oral IDH1 inhibitor that is being evaluated currently in advanced solid tumors (NCT02746081).

Pembrolizumab is an anti-programmed cell death protein 1 (PD-1) antibody that was evaluated in mismatch repair-deficient tumors and demonstrated clinical benefit in a large subset of gastrointestinal malignancies, ultimately being approved by the FDA as an agnostic treatment for microsatellite instability-high (MSI-H) tumors ${ }^{33,34}$. Unfortunately, the MSI-H phenotype is not very common in BTC, and its incidence ranges from $5-10 \%{ }^{35}$. From a total of 11 patients with advanced mismatch repair-deficient BTC enrolled in these trials treated with pembrolizumab, the response rate was $27 \%$, with duration of response ranging between 11 and 20 months $^{36}$. The prevalence of programmed death-ligand 1 (PD-L1) in BTC is similar to MSI and ranges from $5-10 \%{ }^{37,38}$. Combined analysis from two cohorts of advanced BTC patients treated with pembrolizumab provided data for antitumor activity and biomarker selection. In these studies (Keynote 028 and Keynote 158), patients who had failed at least one systemic treatment (no previous immunotherapy allowed), with measurable disease and Eastern Cooperative Oncology Group (ECOG) performance status of $\leq 1$, were treated with pembrolizumab. PD-L1 positivity (membranous PD-L1 expression in $\geq 1 \%$ of tumor and associated inflammatory cells or positive staining in stroma) was not necessary for the Keynote 158 study. All of the 24 patients in Keynote 028 and 61 out of 104 in Keynote 158 had PD-L1 positivity. The response rate ranged from $5.8 \%$ in Keynote 158 to $13 \%$ in Keynote 028 . No greater effectiveness of pembrolizumab was observed in the PD-L1-positive group of patients ${ }^{39}$. Nivolumab, an another anti-PD1 antibody, showed activity in previously treated BTC in a phase II trial. In this multi-institutional study, a total of 54 patients previously treated with at least one but no more than three lines of systemic treatment were evaluated. The median OS was 14.24 months $(95 \%$ 
CI 5.98 months to not reached). PD-L1 expression was associated with prolonged progression-free survival (HR 0.23, 95\% CI $0.10-0.51 ; P<0.001)^{40}$. In order to enhance the activity of checkpoint inhibitors in BTC, randomized trials addressing checkpoint inhibitors combined with chemotherapy and other target drugs in first- and second-line therapy of systemic treatment in advanced BTC are underway (NCT03639935, NCT03101566, NCT03110328, NCT03260712, and NCT04003636).

\section{Conclusion}

New trials evaluating combinations of checkpoint inhibitors with chemotherapy in advanced CCA could enhance the response rate and outcomes of immunotherapy alone. FGFR2 inhibitors are being evaluated in the first-line treatment of patients with FGFR2 fused advanced BTC, and these trials could change the landscape of systemic treatment of CCA in the next few years.
1. National Comprehensive Cancer Network: Hepatobiliary cancers (Version 4. 2019). Accessed February 14, 2020. Reference Source

2. Siegel RL, Miller KD, Jemal A: Cancer statistics, 2019. CA Cancer J Clin 2019; 69(1): 7-34. PubMed Abstract | Publisher Full Text | Faculty Opinions Recommendation

3. Spolverato G, Kim Y, Ejaz A, et al.: Conditional Probability of Long-term Survival After Liver Resection for Intrahepatic Cholangiocarcinoma: A Multiinstitutional Analysis of 535 Patients. JAMA Surg. 2015; 150(6): 538-45. PubMed Abstract | Publisher Full Text

4. Primrose JN, Fox RP, Palmer DH, et al.: Capecitabine compared with observation in resected biliary tract cancer (BILCAP): A randomised, controlled, multicentre, phase 3 study. Lancet Oncol. 2019; 20(5): 663-73. PubMed Abstract | Publisher Full Text | Faculty Opinions Recommendation

5. Takada $\mathrm{T}$, Amano $\mathrm{H}$, Yasuda $\mathrm{H}$, et al.: Is postoperative adjuvant chemotherapy useful for gallbladder carcinoma? A phase III multicenter prospective randomized controlled trial in patients with resected pancreaticobiliary carcinoma. Cancer. 2002; 95(8): 1685-95. PubMed Abstract | Publisher Full Text

6. Ben-Josef E, Guthrie KA, El-Khoueiry AB, et al.: SWOG S0809: A Phase II Intergroup Trial of Adjuvant Capecitabine and Gemcitabine Followed by Radiotherapy and Concurrent Capecitabine in Extrahepatic Cholangiocarcinoma and Gallbladder Carcinoma. J Clin Oncol. 2015; 33(24): 2617-22.

PubMed Abstract | Publisher Full Text | Free Full Text

7. Zaborowski A, Heneghan HM, Fiore B, et al:: Neoadjuvant Chemoradiotherapy and Liver Transplantation for Unresectable Hilar Cholangiocarcinoma: The Irish Experience of the Mayo Protocol. Transplantation. 2020; 104(10): 2097-2104.

PubMed Abstract | Publisher Full Text | Faculty Opinions Recommendation

8. Heimbach JK, Gores GJ, Haddock MG, et al.: Predictors of disease recurrence following neoadjuvant chemoradiotherapy and liver transplantation for unresectable perihilar cholangiocarcinoma. Transplantation. 2006; 82(12): 1703-7.

PubMed Abstract | Publisher Full Text

9. Mantel HTJ, Rosen CB, Heimbach JK, et al.: Vascular complications after orthotopic liver transplantation after neoadjuvant therapy for hilar cholangiocarcinoma. Liver Transpl. 2007; 13(10): 1372-81. PubMed Abstract | Publisher Full Text

10. Murad SD, Kim WR, Harnois DM, et al:: Efficacy of neoadjuvant chemoradiation, followed by liver transplantation, for perihilar cholangiocarcinoma at 12 US centers. Gastroenterology. 2012; 143(1): 88-98.e3; quiz e14. PubMed Abstract | Publisher Full Text | Free Full Text

11. Ethun CG, Lopez-Aguiar AG, Anderson DJ, et al:: Transplantation Versus Resection for Hilar Cholangiocarcinoma: An Argument for Shifting Treatment Paradigms for Resectable Disease. Ann Surg. 2018; 267(5): 797-805. PubMed Abstract | Publisher Full Text | Free Full Text | Faculty Opinions Recommendation

12. Banales JM, Marin JJG, Lamarca A, et al:: Cholangiocarcinoma 2020: The next horizon in mechanisms and management. Nat Rev Gastroenterol Hepatol. 2020; 17(9): 557-88.

PubMed Abstract | Publisher Full Text | Free Full Text |

Faculty Opinions Recommendation
13. Edeline J, Benabdelghani M, Bertaut A, et al:: Gemcitabine and Oxaliplatin Chemotherapy or Surveillance in Resected Biliary Tract Cancer (PRODIGE 12-ACCORD 18-UNICANCER GI): A Randomized Phase III Study. J Clin Oncol. 2019; 37(8): 658-67.

PubMed Abstract | Publisher Full Text | Faculty Opinions Recommendation

14. Ebata T, Hirano S, Konishi M, et al.: Randomized clinical trial of adjuvant gemcitabine chemotherapy versus observation in resected bile duct cancer. Br J Surg. 2018; 105(3): 192-202. PubMed Abstract | Publisher Full Text | Faculty Opinions Recommendation

15. Valle J, Wasan H, Palmer DH: Cisplatin plus gemcitabine versus gemcitabine for biliary tract cancer. N Engl J Med. 2010; 362(14): 1273-81. PubMed Abstract | Publisher Full Text | Faculty Opinions Recommendation

16. Lamarca A, Palmer $\mathrm{DH}$, Wasan HS, et al.: ABC-06 | A randomised phase III, multi-centre, open-label study of active symptom control (ASC) alone or ASC with oxaliplatin / 5-FU chemotherapy (ASC+mFOLFOX) for patients (pts) with locally advanced / metastatic biliary tract cancers (ABC) previously-treated with cisplatin/gemcitabine (CisGem) chemotherapy. JCO. 2019; 37(15_suppl): 4003. Publisher Full Text

17. Bogenberger JM, DeLeon TT, Arora M, et al.: Emerging role of precision medicine in biliary tract cancers. NPJ Precis Oncol. 2018; 2: 21. PubMed Abstract | Publisher Full Text | Free Full Text

18. Lin J, Yang X, Cao Y, et al.: Genomics and translational precision oncology for 803 patients with biliary tract cancer. JCO. 2020; $38: 4589$. Publisher Full Text

19. Nakamura $\mathrm{H}$, Arai $\mathrm{Y}$, Totoki $\mathrm{Y}$, et al.: Genomic spectra of biliary tract cancer. Nat Genet. 2015; 47(9): 1003-10. PubMed Abstract | Publisher Full Text

20. Javle M, Lowery M, Shroff RT, et al.: Phase II Study of BGJ398 in Patients With FGFR-Altered Advanced Cholangiocarcinoma. J Clin Oncol. 2018; 36(3): 276-82. PubMed Abstract | Publisher Full Text | Free Full Text

21. Abou-Alfa GK, Sahai V, Hollebecque A, et al.: Pemigatinib for previously treated, locally advanced or metastatic cholangiocarcinoma: a multicentre, open-label, phase 2 study. Lancet Oncol. 2020; 21(5): 671-84. PubMed Abstract | Publisher Full Text

22. Goyal L, Shi L, Liu LY, et al:: TAS-120 Overcomes Resistance to ATPCompetitive FGFR Inhibitors in Patients with FGFR2 Fusion-Positive Intrahepatic Cholangiocarcinoma. Cancer Discov. 2019; 9(8): 1064-79. PubMed Abstract | Publisher Full Text | Free Full Text | Faculty Opinions Recommendation

23. Goyal L, Saha SK, Liu LY, et al:: Polyclonal Secondary FGFR2 Mutations Drive Acquired Resistance to FGFR Inhibition in Patients with FGFR2 FusionPositive Cholangiocarcinoma. Cancer Discov. 2017; 7(3): 252-63. PubMed Abstract | Publisher Full Text | Free Full Text

24. Krook MA, Bonneville R, Chen HZ, et al:: Tumor heterogeneity and acquired drug resistance in FGFR2-fusion-positive cholangiocarcinoma through rapid research autopsy. Cold Spring Harb Mol Case Stud. 2019; 5(4): a004002. PubMed Abstract | Publisher Full Text | Free Full Text | Faculty Opinions Recommendation

25. Tran B, Meric-Bernstam F, Arkenau HT, et al.: Efficacy of TAS-120, an irreversible fibroblast growth factor receptor inhibitor (FGFRi), in patients with cholangiocarcinoma and FGFR pathway alterations previously treated with 
chemotherapy and other FGFRi's. Ann Oncol. 2018; 29(SUPPLEMENT 9): ix49-ix50.

Publisher Full Tex

26. Voss MH, Hierro C, Heist RS, et al:: A Phase I, Open-Label, Multicenter, Dose-escalation Study of the Oral Selective FGFR Inhibitor Debio 1347 in Patients with Advanced Solid Tumors Harboring FGFR Gene Alterations. Clin Cancer Res. 2019; 25(9): 2699-707.

PubMed Abstract | Publisher Full Text | Faculty Opinions Recommendation

27. Chen YY, Park JO, Su WC, et al:: Preliminary results of a ph2a study to evaluate the clinical efficacy and safety of erdafitinib in Asian patients with biomarke selected advanced cholangiocarcinoma (CCA). Ann Oncol. 2018; 29: viii209. Publisher Full Text

28. Mazzaferro V, El-Rayes BF, Droz Dit Busset M, et al:: Derazantinib (ARQ 087) in advanced or inoperable FGFR2 gene fusion-positive intrahepatic cholangiocarcinoma. Br J Cancer. 2019; 120(2): 165-71. PubMed Abstract | Publisher Full Text | Free Full Text | Faculty Opinions Recommendation

29. Borger DR, Tanabe KK, Fan KC, et al.: Frequent mutation of isocitrate dehydrogenase $(I D H) 1$ and IDH2 in cholangiocarcinoma identified through broad-based tumor genotyping. Oncologist. 2012; 17(1): 72-9. PubMed Abstract | Publisher Full Text | Free Full Text

30. Goyal L, Govindan A, Sheth RA, et al.: Prognosis and Clinicopathologic Features of Patients With Advanced Stage Isocitrate Dehydrogenase (IDH) Mutant and IDH Wild-Type Intrahepatic Cholangiocarcinoma. Oncologist. 2015; 20(9): 1019-27.

PubMed Abstract | Publisher Full Text | Free Full Text

31. Lowery MA, Burris HA, Janku F, et al:: Safety and activity of ivosidenib in patients with IDH1-mutant advanced cholangiocarcinoma: a phase 1 study. Lancet Gastroenterol Hepatol. 2019; 4(9): 711-20.

PubMed Abstract | Publisher Full Text | Faculty Opinions Recommendation

32. Abou-Alfa GK, Macarulla T, Javle MM, et al:: Ivosidenib in IDH1-mutant, chemotherapy-refractory cholangiocarcinoma (ClarlDHy): a multicentre, randomised, double-blind, placebo-controlled, phase 3 study. Lancet Oncol. 2020; 21(6): 796-807

PubMed Abstract | Publisher Full Text | Free Full Text
33. Le DT, Uram JN, Wang H, et al:: PD-1 Blockade in Tumors with MismatchRepair Deficiency. N Engl J Med. 2015; 372(26): 2509-20. PubMed Abstract | Publisher Full Text | Free Full Text | Faculty Opinions Recommendation

34. Le DT, Durham JN, Smith KN, et al.: Mismatch repair deficiency predicts response of solid tumors to PD-1 blockade. Science. 2017; 357(6349): 409-13. PubMed Abstract | Publisher Full Text | Free Full Text | Faculty Opinions Recommendation

35. Silva VWK, Askan G, Daniel TD, et al:: Biliary carcinomas: pathology and the role of DNA mismatch repair deficiency. Chin Clin Oncol. 2016; 5(5): 62. PubMed Abstract | Publisher Full Text

36. Lemery S, Keegan P, Pazdur R: First FDA Approval Agnostic of Cancer Site - When a Biomarker Defines the Indication. N Engl J Med. 2017; 377(15): 1409-12.

PubMed Abstract | Publisher Full Text

37. Kriegsmann M, Roessler S, Kriegsmann K, et al.: Programmed cell death ligand 1 (PD-L1, CD274) in cholangiocarcinoma - correlation with clinicopathological data and comparison of antibodies. BMC Cancer. 2019; 19(1): 72

PubMed Abstract | Publisher Full Text | Free Full Text | Faculty Opinions Recommendation

38. Mody K, Starr J, Saul M, et al:: Patterns and genomic correlates of PD-L1 expression in patients with biliary tract cancers. J Gastrointest Oncol. 2019; 10(6): 1099-109.

PubMed Abstract | Publisher Full Text | Free Full Text |

Faculty Opinions Recommendation

39. Bang YJ, Ueno M, Malka D, et al.: Pembrolizumab (pembro) for advanced biliary adenocarcinoma: Results from the KEYNOTE-028 (KN028) and KEYNOTE-158 (KN158) basket studies. JCO. 2019; 37(15): 4079. Publisher Full Text

40. Kim RD, Chung V, Alese OB, et al.: A Phase 2 Multi-institutional Study of Nivolumab for Patients With Advanced Refractory Biliary Tract Cancer. JAMA Oncol. 2020; 6(6): 888-94.

PubMed Abstract | Publisher Full Text | Free Full Text |

Faculty Opinions Recommendation 